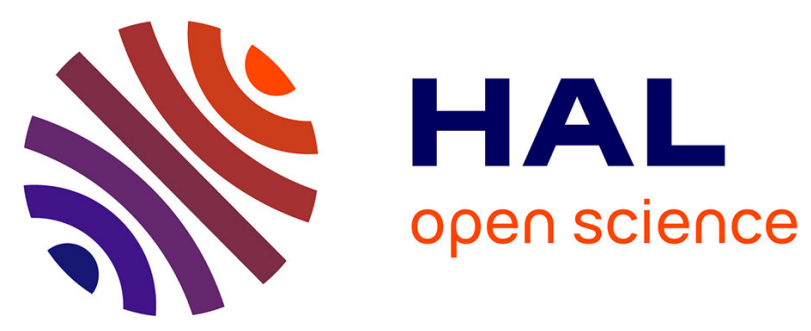

\title{
Time-Course Diffusion of Hydrogen Peroxide Through Human Dentin: Clinical Significance for Young Tooth Internal Bleaching
}

Jean Camps, Hélène de Franceschi, Fatiha Idir, Christelle Roland, Imad About

\section{- To cite this version:}

Jean Camps, Hélène de Franceschi, Fatiha Idir, Christelle Roland, Imad About. Time-Course Diffusion of Hydrogen Peroxide Through Human Dentin: Clinical Significance for Young Tooth Internal Bleaching. Journal of Endodontics, 2007, 33 (4), pp.455-459. 10.1016/j.joen.2006.12.006 . hal-03552081

\author{
HAL Id: hal-03552081 \\ https://hal.science/hal-03552081
}

Submitted on 2 Feb 2022

HAL is a multi-disciplinary open access archive for the deposit and dissemination of scientific research documents, whether they are published or not. The documents may come from teaching and research institutions in France or abroad, or from public or private research centers.
L'archive ouverte pluridisciplinaire HAL, est destinée au dépôt et à la diffusion de documents scientifiques de niveau recherche, publiés ou non, émanant des établissements d'enseignement et de recherche français ou étrangers, des laboratoires publics ou privés. 


\title{
Time-Course Diffusion of Hydrogen Peroxide Through Human Dentin: Clinical Significance for Young Tooth Internal Bleaching
}

\author{
Jean Camps, DCD, PbD, * Hélène de Franceschi, DCD, * Fatiba Idir, DCD, * \\ Christelle Roland, DCD, * and Imad About, MS, PbD*
}

\begin{abstract}
The purpose of this study was to record the time-course diffusion of hydrogen peroxide through human dentin from a peroxide carbamide gel designed for the walking bleach technique in order to determine its optimal renewal time. It was considered that the optimal renewal rate corresponded to the time necessary to achieve $80 \%$ of the maximal diffusion because a much longer time does not involve further significant diffusion. Thirty-six freshly extracted human premolars were used for this study. Eighteen were extracted for orthodontic reasons on patients under 20 years old (youngteeth group). Eighteen were extracted for periodontal reasons on patients between 40 and 60 years old (old-teeth group). The teeth were endodontically treated, and a flat defect was created at the enamelcementum junction. The teeth were suspended in vials containing water, and the access cavities were filled with $20 \mu \mathrm{L}$ of $20 \%$ hydrogen peroxide gel. The amount of diffusing hydrogen peroxide was assessed at 1 hour, 24 hours, 48 hours, and 120 hours. The diffusive flux and the maximal diffusion were calculated as well as the optimal renewal time. Hydrogen peroxide diffusion through young teeth lasted 352 hours but lasted 291 hours through old teeth. Diffusive flux and maximal diffusion were higher through young teeth than through old teeth. The optimal renewal time for young teeth was 33 hours and for old teeth was 18 hours.
\end{abstract}

\section{Key Words}

Dentin, diffusion, hydrogen peroxide
$T$ he intracoronal bleaching of pulpless teeth with hydrogen peroxide has been introduced in the 19th century (1). It was only in 1963 that the term "walking bleach" was given to the technique, which is still used (2). Applying this technique implies hydrogen peroxide diffusion through dentin in order to whiten discolored teeth. Hydrogen peroxide is further decomposed into oxidizing agents such as hydroxyl radicals (3) and active oxygen (4). These agents aim at the discoloration of the staining agents resulting from the release of hemoglobin and intratubular diffusion of hemoglobin byproducts (5).

A shortcoming of such a whitening technique is the cervical root resorption that is caused by bleaching in 3.9\% of the cases (6). The mechanisms involved in root resorption of discolored teeth, after walking bleach, are not clearly understood (7). However, several studies have shown that hydrogen peroxide may be responsible for root resorption. External resorptions have been shown in an animal study only 3 months after internal bleaching when $30 \%$ hydrogen peroxide was used and heated (8). This resorption is a major consequence in young patients after traumatic injury of front teeth that may lead to tooth loss (9). The thermocatalytic technique also leads to the development of external root resorptions (10). These observations are caused by the fact that hydrogen peroxide diffusion through dentin increases on increasing the concentration $(11,12)$ and temperature $(13)$. To reduce the external root-resorption risk, hydrogen peroxide can be replaced by carbamide peroxide, which releases hydrogen peroxide more slowly and at lower concentrations than hydrogen peroxide (14).

Dentin is a permeable structure that allows diffusion of molecules, such as hydrogen peroxide, resulting from peroxide carbamide degradation (15). The diffusion through dentin follows Fick's second law (16)

$$
\mathrm{Js}=\mathrm{A} \cdot \mathrm{D} \cdot \frac{\Delta \mathrm{C}}{\Delta \mathrm{x}}
$$

with: Js = diffusive flux of solute $(\mathrm{mol} / \mathrm{s})$

$\mathrm{A}=$ Surface area available for diffusion $\left(\mathrm{m}^{2}\right)$

$\mathrm{D}=$ Diffusion coefficient $\left(\mathrm{m}^{2} / \mathrm{s}\right)$

$\mathrm{C}=$ Concentration $\left(\mathrm{mol} / \mathrm{m}^{3}\right)$

$\Delta \mathrm{x}=$ Diffusion distance $(\mathrm{m})$

It can be concluded, from the equation, that the diffusion stops when the concentration of hydrogen peroxide is equivalent on both sides of the dentin. It would be interesting, from a clinical point of view, to know the time-course diffusion of hydrogen peroxide from peroxide carbamide because the renewal rate of the bleaching agent during walking bleach remains empirical (7). For example, Ultradent Product Inc. (South Jordan, UT) recommends renewing Opalesence Endo, a 35\% hydrogen peroxide gel designed for the walking bleach technique, every 3 to 5 days until the desired color is achieved. Usually, this renewal takes place every week for practical reasons until a satisfactory esthetic result is obtained. In vivo, the degradation of peroxide carbamide gel used for vital bleaching has been investigated (17). However, to our knowledge, the diffusive flux of hydrogen peroxide from peroxide carbamide through dentin, in the walking bleach technique, still remains to be investigated. 
The purpose of this study was to record the time-course diffusion of hydrogen peroxide through human dentin, from a peroxide carbamide gel designed for the walking bleach technique, in order to determine its optimal renewal rate.

\section{Tooth Preparation}

\section{Materials and Methods}

Freshly extracted human premolars were used for this study. The selected teeth did not present any detectable caries or restoration. The teeth were carefully removed with forceps, and soft-tissue remnants were gently cleaned without damaging the radicular cementum. The teeth were examined under a binocular loop to eliminate the teeth with signs of cracks and those with cementum defects. They were stored in bidistilled water at $4^{\circ} \mathrm{C}$ and used within 1 month after extraction.

They were divided into two groups called "young teeth" and "old teeth" according to the patient age: (1) young teeth extracted for orthodontic reasons (age ranging from 12 to 20 years $[n=18]$ ) and (2) old teeth extracted for periodontal reasons (age ranging from 41 to 62 years $[n=18]$ ).

After preparing an access cavity, a size $10 \mathrm{~K}$-file was introduced into the canal in order to radiographically measure the working length and to clinically check the patency of the foramen. The root canals were prepared by the same operator to the cementodentinal junction with a ProFile device (Dentsply/Maillefer, Ballaigues, Switzerland) using a reduction handpiece coupled to an electric motor. A size $10 \mathrm{~K}$-file was used between each ProFile to ensure the apical patency. Two milliliters of $2.5 \% \mathrm{NaOCl}$ were delivered with a 27 -gauge needle after each file. The final rinse was performed with phosphate-buffered saline (PBS). The teeth were then filled by using the lateral condensation technique with a zinc oxide-eugenol-based root canal sealer (Sealite; Pierre Rolland, Merignac, France) and gutta-percha points (Denstply/Maillefer). The teeth were then stored for 1 day in an incubator, on a gauze sponge saturated with $\mathrm{PBS}$, at $37^{\circ} \mathrm{C}$ and $100 \%$ humidity to allow setting of the root filling materials.

\section{Study Model}

A round carbide bur, rotating at a low speed, was used to eliminate the filling material from the first $2 \mathrm{~mm}$ of the root and $1 \mathrm{~mm}$ of Cavit (3M ESPE, Seefeld, Germany) was placed. The cavity access was then thoroughly rinsed with PBS and visually inspected to eliminate any remnants. The outer surface of the teeth was carefully covered with two layers of thick nail varnish to fill any undetected defect. A rectangular class $\mathrm{V}$ cavity, $4 \mathrm{~mm}$ long and $2 \mathrm{~mm}$ high, was created above the cementumenamel junction by using a high-speed diamond bur. The remaining dentine was measured with calipers to leave a 1-mm thickness. The teeth were placed in vials containing $1 \mathrm{~mL}$ of bidistilled water in such a way that the class $V$ cavities were below the water level allowing diffusion from the pulp chamber toward the water that was called the receiving medium.

\section{Determination of Hydrogen Peroxide Diffusion in Function of Time}

The same amount of bleaching agent was placed within the pulp chamber of each tooth: $20 \mu \mathrm{L}$ of $20 \%$ OPALESCENCE PF (Ultradent). The receiving medium was removed at 1 hour, 24 hours, 48 hours, and 120 hours and immediately replaced by $1 \mathrm{~mL}$ of bidistilled water. The amount of $\mathrm{H}_{2} \mathrm{O}_{2}$ that diffused through dentin at 1 hour, 24 hours, 48 hours, and 120 hours was measured with a colorimetric method based on an oxidation-reduction reaction.
Four additional teeth prepared and tested under the same conditions but without class $V$ cavities were used as the negative control to ensure that no leak could occur.

\section{Hydrogen Peroxide Measurements Method}

Quantification of hydrogen peroxide present within the receiving medium was done using an oxidation-reduction reaction (18). One milliliter of $35 \% \mathrm{H}_{2} \mathrm{O}_{2}$ was added to $0.2 \mathrm{~mL}$ of $10 \mathrm{mmol} / \mathrm{L}$ ferrous ammonium chloride. The released ferric ion reacted with $0.1 \mathrm{~mL}$ of 2.5 $\mathrm{mmol} / \mathrm{L}$ potassium thiocyanate to form a red-colored ferrithiocyanate complex. Serial dilutions of hydrogen peroxide (Merck, Darmstadt, Germany) in bidistilled water, from $1 \mathrm{~mol}$ to $10^{-9} \mathrm{~mol}$, were used to establish the standard curve. The optical density of the final solution, read at $480 \mathrm{~nm}$, was proportional to the amount of $\mathrm{H}_{2} \mathrm{O}_{2}$ in the medium. The concentration of hydrogen peroxide in the different receiving media was calculated from the standard curve equation. All measurements were done in triplicate and averaged. The reagents' readings served as a negative control.

\section{Statistical Analysis}

To establish the standard curve, a linear regression, by the method of the least squares, was sought between the hydrogen peroxide quantity and the solution optical density. The significance level was set at 0.05 . The concentration variation over time was analyzed. A regression was sought between hydrogen peroxide concentration and diffusion time: $\mathrm{f}(\mathrm{t})$. The significance level was set at 0.05 .

The estimated time necessary for complete diffusion (EDT), through young and old dentin, was calculated from $f(t)$. This was not the time at which the curve $\mathrm{f}(\mathrm{t})$ crosses the $\mathrm{x}$-axis because $\mathrm{f}(\mathrm{t})$ was exponential. This means that the diffusion is never complete and that the curve never crosses the x-axis. The EDT was the time at which the diffusion was close to zero and the value of $10^{-10} \mathrm{~mol} / \mathrm{L}$ was retained as the diffusion end.

The estimated maximal diffusion was also determined from the data of this work. The maximal diffusion was the area between the same curve $f(t)$ and the $x$-axis given by the definite integral between the beginning of diffusion and EDT:

$$
\int_{0}^{E D T} \mathrm{f}(\mathrm{t})
$$

The optimal renewal time was then determined from the equation $f(t)$. It was considered that the renewal time corresponded to the time necessary to achieve $80 \%$ of the estimated maximal diffusion because a much longer time will only lead to the remaining $20 \%$. To compare hydrogen peroxide diffusion through young and old dentin, an analysis of variance was performed. The significance level was set at 0.05 .

\section{Standard Gurve}

\section{Results}

There was a linear correlation between hydrogen peroxide quantity and the optical density $(\mathrm{p}<0.001)$. The equation was $\mathrm{y}=235.41 \mathrm{x}$ +0.0413 , and the Pearson coefficient was $\mathrm{R}^{2}=0.98$.

\section{Concentration Variation Over Time}

In young teeth, there was a rapid diffusion within the first hour $(1.1$ $\left.\times 10^{-6} \mathrm{~mol} / \mathrm{L}\right)$ and twice lower after 24 hours $\left(0.63 \times 10^{-6} \mathrm{~mol} / \mathrm{L}\right)$. The diffusion was still noticeable after 48 hours $\left(0.23 \times 10^{-6} \mathrm{~mol} / \mathrm{L}\right)$ but negligible at 120 hours $\left(0.05 \times 10^{-6} \mathrm{~mol} / \mathrm{L}\right)$ (Table 1$)$. There was a statistically significant inverse exponential correlation between the concentration in hydrogen peroxide and time for young teeth of which the equation was as follows: $y=10^{-6} \times \mathrm{e}^{-0.026 \mathrm{t}}(\mathrm{p}<0.01)$, and the Pearson coefficient was $\mathrm{R}^{2}=0.98$ (Fig. 1). 
TABLE 1. Hydrogen Peroxide Diffusion Through Young Human Dentin, From a 20\% Peroxide Carbamide Gel

\begin{tabular}{lcccc}
\hline & $\begin{array}{c}\text { Mean } \\
\text { Amount of } \\
\mathrm{H}_{\mathbf{2}} \mathbf{O}_{\mathbf{2}} \text { (mole) }\end{array}$ & $\begin{array}{c}\text { Standard } \\
\text { Deviation }\end{array}$ & Minimum & Maximal \\
\hline to & 0 & 0 & 0 & 0 \\
$1 \mathrm{~h}$ & $1.1 \times 10^{-6}$ & $9.7 \times 10^{-7}$ & $6.3 \times 10^{-8}$ & $2.7 \times 10^{-6}$ \\
$24 \mathrm{~h}$ & $6.3 \times 10^{-7}$ & $4.7 \times 10^{-7}$ & $2.1 \times 10^{-8}$ & $1.6 \times 10^{-6}$ \\
$48 \mathrm{~h}$ & $2.3 \times 10^{-7}$ & $1.7 \times 10^{-7}$ & 0 & $5.7 \times 10^{-7}$ \\
$120 \mathrm{~h}$ & $5.0 \times 10^{-8}$ & $6.6 \times 10^{-8}$ & 0 & $2.3 \times 10^{-7}$ \\
\hline
\end{tabular}

The diffusion is high during the first hour before slowing down from 24 hours to 120 hours.

In the old-teeth group, there was a rapid diffusion within the first hour $\left(6.1 \times 10^{-7} \mathrm{~mol} / \mathrm{L}\right)$, which remained almost stable at 24 hours $\left(4.3 \times 10^{-7} \mathrm{~mol} / \mathrm{L}\right)$. However, the diffusion decreased at 48 hours $\left(0.48 \times 10-{ }^{7} \mathrm{~mol} / \mathrm{L}\right)$ and reached the detection limit at 120 hours $\left(0.081 \times 10-{ }^{7} \mathrm{~mol} / \mathrm{L}\right)($ Table 2$)$.

There was also a statistically significant inverse exponential correlation between the concentration in hydrogen peroxide and time for the old teeth of which the equation was as follows: $y=6 \times 10^{-7} \times \mathrm{e}^{-0.037 \mathrm{t}}$ $\left(\mathrm{p}<0.01\right.$ ), and the Pearson coefficient was $\mathrm{R}^{2}=0.93$ (Fig. 2).

\section{EDT Galculation}

The diffusion time was longer for young teeth (352 hours) than for old teeth (291 hours). In young teeth, EDT was calculated from the following equation: $10^{-10}=10^{-6} \mathrm{e}^{-0.026 \mathrm{t}}$. In this case, the EDT was 352 hours; this means that the diffusion stops after 352 hours. In old teeth, EDT was calculated from the following equation: $10^{-10}=6 \times$ $10^{-} \mathrm{e}^{-0.037 \mathrm{t}}$. The EDT was equivalent to 291 hours. This indicates that the diffusion stops after 291 hours.

\section{Calculation of the Maximal Hydrogen Peroxide Diffusion}

Maximal hydrogen peroxide diffusion was higher for young teeth $\left(2.31^{-06} \mathrm{~mol}\right)$ than for old teeth $\left(1.14 \times 10^{-6} \mathrm{~mol}\right)$. In young teeth, the value was calculated from the following equation:

$$
\int_{t=0}^{t=352}\left(10^{-6} \times \mathrm{e}^{-0.026 \mathrm{t}}\right)
$$

and this value corresponds to $2.31^{-06}$ mol. Clearly, this means that in 352 hours, $2.31^{-06}$ moles can diffuse through young dentin, from the $20 \%$ peroxide carbamide gel. In old teeth, the value was calculated from the following equation:

$$
\int_{t=0}^{t=291}\left(6 \times 10^{-7} \times \mathrm{e}^{-0.037 t}\right)
$$

and the maximal hydrogen peroxide diffusion corresponds to 1.14 $\times 10^{-6} \mathrm{~mol}$. This reveals that, in 291 hours, $1.14 \times 10^{-6} \mathrm{~mol}$ can

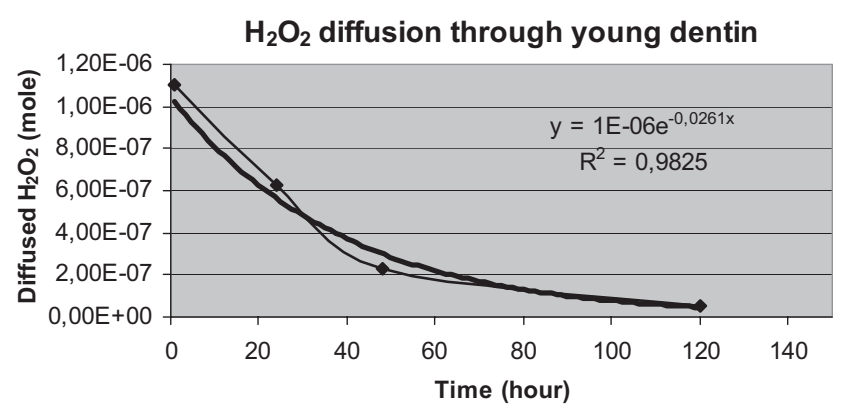

Figure 1. Correlation between hydrogen peroxide diffusion through young dentin and time. Diffusion is the inverse of an exponential curve $\left(y=10^{-6} \times \mathrm{e}^{-0.026 \mathrm{t})}\right.$ with an asymptote never crossing the $\mathrm{x}$-axis.
TABLE 2. Hydrogen Peroxide Diffusion Through Old Human Dentin, From a 20\% Peroxide Carbamide Gel

\begin{tabular}{lcccc}
\hline & $\begin{array}{c}\text { Mean } \\
\text { Amount } \\
\text { of } \mathrm{H}^{2} \mathrm{O}_{2} \\
(\mathrm{~mole})\end{array}$ & $\begin{array}{c}\text { Standard } \\
\text { Deviation }\end{array}$ & Minimum & Maximal \\
\hline to & 0 & 0 & 0 & 0 \\
$1 \mathrm{~h}$ & $6.1 \times 10^{-7}$ & $4.3 \times 10^{-7}$ & 0 & $1.2 \times 10^{-6}$ \\
$24 \mathrm{~h}$ & $4.3 \times 10^{-7}$ & $1.0 \times 10^{-7}$ & 0 & $8.7 \times 10^{-7}$ \\
$48 \mathrm{~h}$ & $4.8 \times 10^{-8}$ & $5.1 \times 10^{-8}$ & 0 & $1.7 \times 10^{-7}$ \\
$120 \mathrm{~h}$ & $8.1 \times 10^{-9}$ & $1.7 \times 10^{-8}$ & 0 & $6.4 \times 10^{-8}$ \\
\hline
\end{tabular}

The diffusion is high during the first hour before slowing down from 24 hours to 120 hours.

diffuse through old dentin, from the same $20 \%$ peroxide carbamide gel.

These EDT and maximal diffusions are summarized in Table 3.

\section{Galculation of the Optimal Renewal Time}

To calculate the optimal renewal time, a diffusion corresponding to $80 \%$ of the maximal diffusion values was taken into consideration. Thus, in young teeth, the optimal renewal time, as calculated from the equation $2.31^{-06} \times 80 \%=10^{-6} \times \mathrm{e}^{-0.026 \mathrm{t}}$, was 33 hours. This value reveals that the bleaching agents should be renewed every 33 hours to maintain a constant high level of diffusion in young teeth. In old teeth, this value correlates to 18 hours, as calculated from the following equation: $1.14 \times 10^{-6} \times 80 \%=6 \times 10^{-7} \mathrm{e}^{-0.037 \mathrm{t}}$. This means that, in old teeth, the hydrogen peroxide gel should be replaced every 18 hours. For a better illustration of the significance of these calculations, the cumulative curve of hydrogen peroxide diffusion was established to point out the optimal renewal time (Fig. 3).

\section{Intergroup Comparison}

The four negative samples did not show any hydrogen peroxide diffusion through dentin. The analysis of variance showed a statistically significant higher diffusive hydrogen peroxide flux through the youngteeth group $(\mathrm{p}=0.04)$. The cumulative amount of diffused hydrogen peroxide was twice as high in young teeth $\left(2.01 \times 10^{-6} \mathrm{~mol}\right)$ than in old teeth $\left(1.09 \times 10^{-6} \mathrm{~mol}\right)$ (Fig. 3).

\section{Discussion}

One of the major concerns of a practitioner undertaking a walking bleach on a discolored pulpless tooth is to find a compromise between the esthetic result, the risk of initiating an external root resorption, and the time necessary to obtain the best esthetic result. Using peroxide carbamide instead of hydrogen peroxide is a good compromise because this materials releases hydrogen peroxide at a lower rate and at lower concentrations than hydrogen peroxide (14) and gives satisfying es-

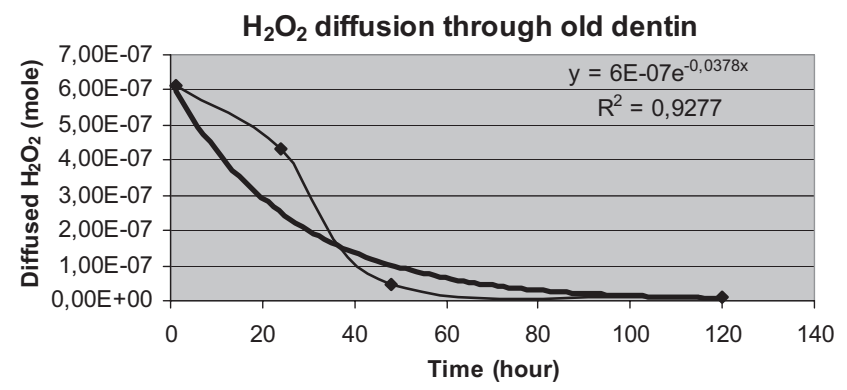

Figure 2. Correlation between hydrogen peroxide diffusion through old dentin and time. Diffusion is the inverse of an exponential $\left(y=6 \times 10^{-7} \mathrm{e}^{-0.037 t)}\right.$ with an asymptote never crossing the $\mathrm{x}$-axis. 
thetic results (19). That is why a $20 \%$ carbamide peroxide gel, commercially designed for the walking bleach technique, was used in this work. The design of the study was derived from a common design using extracted premolars (8). The main difference lies in the use of two groups of teeth in function of the patient age. This study demonstrated that diffusion through young dentin was twice as high as through old dentin. This suggests that young teeth should respond better to the walking bleach technique than the old teeth (20). Building homogeneous groups of teeth with the same dentin permeability is important; some authors compared different $10 \%$ peroxide carbamide gels and found statistically different hydrogen peroxide diffusions (21). They concluded that variations in additional agents modified the outcome of the study, but they did not check out differences in dentin permeability.

The correlation analysis showed that the diffusion rate was not linear but inversely exponential. Figures 1 and 2 clearly show a linear correlation between hydrogen peroxide diffusion and time during the first part of the experimentation. After this, the diffusion slows down and almost stops after 120 hours. From a clinical point of view, this means that maintaining the bleaching product beyond the optimal renewal rate ( $80 \%$ of the maximal diffusion) does not involve further significant diffusion. This also means, from a theoretical point of view, that the coefficients representing hydrogen peroxide diffusion through dentin, such as D and P, must be calculated from data resulting from diffusion times shorter than the optimal renewal rate to be clinically relevant. For example $\mathrm{P}$, for young teeth, calculated from the data at 24 hours is 3.12 $\times 10^{-6} \mathrm{~cm} / \mathrm{min}$ but is of $0.75 \times 10^{-6} \mathrm{~cm} / \mathrm{min}$ when calculated from data recorded at 120 hours. This also explains why a linear correlation between hydrogen peroxide diffusion and time should be established before drawing any conclusion from this type of work.

Some studies already recorded hydrogen peroxide diffusion through dentin from a peroxide carbamide gel but only at one time point, generally after 30 minutes or 1 hour (22). Unfortunately, comparisons among studies are not valid when they are based on comparisons between hydrogen peroxide diffusion because they depend on the parameters of the study (16). Only comparisons among studies relying on D (diffusion coefficient) or P (permeability parameter) are valid because this calculation cancels out the parameters of the study such as remaining dentin thickness or initial concentration. The present work showed that the complete hydrogen peroxide diffusion, from a $20 \%$ peroxide carbamide gel, took about 15 days ( 352 hours) through young dentin and about 12 days (291 hours) through old dentin. This is in agreement with another study that showed a small diffusion at 7 days with another carbamide peroxide gel (14). The maximal diffusion obtained after this diffusion time was $2.31 \times 10^{-6}$ mol for the young teeth and $1.14 \times 10^{-6} \mathrm{~mol}$ for the old teeth. From a theoretical point of view, the diffusion stops when the same concentration is reached on both sides of dentin. Therefore, the maximal diffusion should be the same for both groups because the driving concentration was the same on young and old teeth. In fact, the difference is related to a higher diffusion rate through young dentin than through old dentin associated with a longer

TABLE 3. Time Necessary for Diffusion and Maximal Diffusion of Hydrogen Peroxide, From a 20\% Peroxide Carbamide Gel, Through Young and Old Dentin

\begin{tabular}{lcc}
\hline & $\begin{array}{c}\text { Time Necessary } \\
\text { for Complete } \\
\text { Diffusion }\end{array}$ & Maximal Diffusion \\
\hline Young dentin & 352 hours & $2.31 \times 10^{-6} \mathrm{~mol}$ \\
Old dentin & 291 hours & $1.14 \times 10^{-6} \mathrm{~mol}$ \\
\hline $\begin{array}{l}\text { Diffusion through young dentin is longer than through old dentin and leads to a } 2.02 \text { times higher } \\
\text { diffusion. }\end{array}$
\end{tabular}

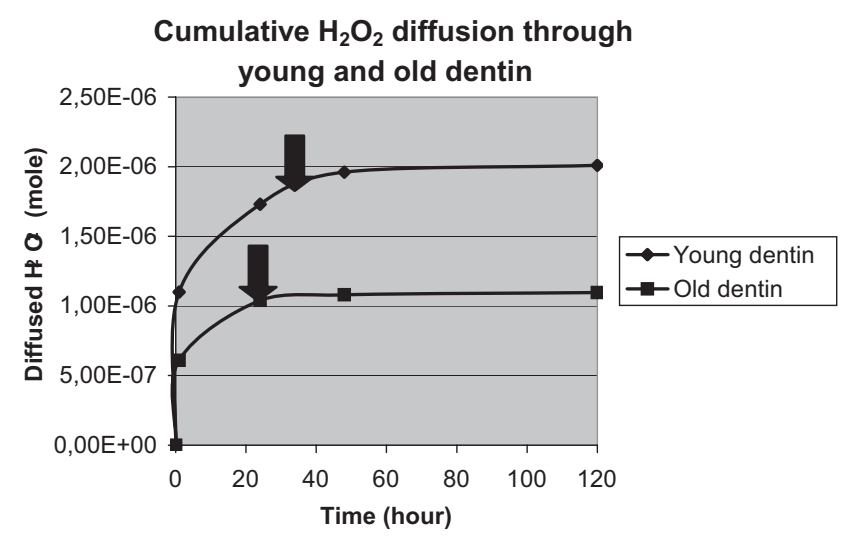

Figure 3. Cumulative hydrogen peroxide diffusion through young and old dentin. Diffusion through young dentin is significantly higher than through old dentin $(p=0.04)$. The arrows represent the optimal renewal time.

diffusion time (352 hours vs. 291 hours). Diffusion through old dentin may be reduced by a small dentinal tubule diameter and by intratubular deposits that increase the possibility of interaction between the diffusing molecule and tubule contents (23).

This study was undertaken to record the time-course diffusion of hydrogen peroxide through human dentin in order to determine the optimal renewal time. In this work, the optimal renewal rate was arbitrarily defined as the time necessary to obtain a diffusion equivalent to $80 \%$ of the maximal diffusion. Because the relationship between the diffusion and time is inversely exponential, this value corresponds to the point beyond which a longer diffusion time does not bring any clinically significant effect. The optimal renewal time was 33 hours for young teeth and 18 hours for old teeth, respectively. These results have other clinical implications. First, a dentist aiming at obtaining the fastest results, without spending too much chairtime, should renew the peroxide carbamide gel every 18 hours in old teeth and every 33 hours in young teeth until achieving the desired esthetic result. In practice, this renewal can be done every day in old teeth and every other day in young teeth. This will not decrease the appointment number but will accelerate the total treatment time and the possible subsequent prosthetic treatment in case of failure. A longer renewal rate, such as a weekly rate, frequently used for convenience reasons, will delay the result because the supplementary days will not lead to any significant hydrogen peroxide diffusion. However, a daily renewal rate on young teeth will shorten the treatment compared with the 2-day regimen, but renewing the peroxide carbamide gel every day is fastidious and chair-time consuming. Therefore, it can be recommended to renew the peroxide carbamide every day on old teeth and every other day on young teeth. Leaving carbamide peroxide for a longer period of time in case of refractory tooth makes no sense. Additional renewals would be preferred in this situation. Second, hydrogen peroxide diffusion through young dentin is $2.02\left(2.31 \times 10^{-6}\right.$ / $1.14 \times 10^{-6)}$ times higher than through old dentin. This means that the whitening treatments performed on young teeth will take less time than on the old teeth. This is very interesting because the walking bleach technique is generally used to whiten traumatized front young teeth. Unfortunately, few clinical studies exist stratifying the results obtained according to the ages of the patients.

\section{References}

1. Halan AW. The removal of stains caused by the administration of medicinal agents and the bleaching of pulpless teeth. Am J Dent Sci 1884;18:521.

2. Nutting EB, Poe GS. Chemical bleaching of discoloured endodontically treated teeth. Dent Clin North Am 1967;655-62. 
3. Farmer DS, Burcham P, Marin PD. The ability of thiourea to scavenge hydrogen peroxide and hydroxil radicals during the intra-coronal bleaching of bloodstained root-filled teeth. Austral Dent J 2006;51:146-52.

4. Kashima-Tanaka M, Tsujimoto Y, Kawamoto K, Senda N, Ito K, Yamazaki M. Generation of free radicals and/or active oxygen by light or laser irradiation of hydrogen peroxide or sodium hypochlorite. J Endod 2003;29:141-3.

5. Marin PD, Bartold PM, Heithersay GS. Tooth discoloration by blood: an in vitro histochemical study. Endod Dent Ttraumatol 1997;13:132-8.

6. Heithersay GS, Dahlstrom SW, Marin PD. Incidence of invasive cervical resorption in bleached root-filled teeth. Austral Dent J 1994;39:82-7.

7. Attin T, Paqué F, Ajam F, Lennon AM. Review of the current status of tooth whitening with the walking bleach technique. Int Endod J 2006;36:313-29.

8. Rotstein I, Friedman S, Mor C, Kaltznelson J, Sommer M, Bab I. Histological characterization of bleaching-induced external resorption in dogs. J Endod $1991 ; 17: 436-41$

9. Trope M. Luxation, injuries and external root resorption- etiology, treatment and prognosis. J Calif Dent Assoc 2000;28:860-6

10. Madison S, Walton R. Cervical root resorption following bleaching of endodontically treated teeth. J Endod 1990;16:570-4.

11. Gökay 0, Tunçbilek M, Ertan R. Penetration of the pulp chamber by carbamide peroxide bleaching agents on teeth restored with a composite resin. J Oral Rehab 2000;27:428-31

12. Gökay 0 , Müjdeci A, Algin E. Peroxide penetration into the pulp from whitening strips. J Endod 2004;30:887-9.
13. Bowles W, Ugwuneri Z. Pulp chamber penetration by hydrogen peroxide following vital bleaching procedures. J Endod 1987;13:375-7.

14. Lee GP, Lee MY, Lum SOY, Poh RCS, Lim KC. Extraradicular diffusion of hydrogen peroxide and $\mathrm{pH}$ changes associated with intracoronal bleaching of discoloured teeth using different bleaching agents. Int Endod J 2004;37:500-6.

15. Merchant VA, Livingston MJ, Pashley DH. Dentin permeation: Comparison of diffusion with filtration. J Dent Res 1977;56:1161-4.

16. Pashley DH. Dentin-predentin complex and its permeability: Physiologic overview J Dent Res 1985;64:613-20.

17. Matis BA, Yousef M, Cochran MA, Eckert GL. Degradation of bleaching gels in vivo as a function of tray design and carbamide peroxide concentration. Oper Dent $2002 ; 27: 12-8$

18. Thurman RG, Ley HG, Scholz R. Hepatic microsomal ethanol oxidation: hydrogen peroxide formation and the role of catalase. Eur J Biochem 1972;25:420 -30.

19. Nathoo S, Stewart B, Petrone ME, et al. Comparative clinical investigation of the tooth whitening efficacy of two whitening gels. J Clin Dent 2003;14:64-9.

20. Freiglin B. A 6-year recall study of clinically chemically bleached teeth. Oral Surg Oral Med Oral Pathol 1987;63:616-23.

21. Thitinanthapan W, Satamanont P, Vongsavan N. In vitro penetration of the pulp chamber by three brands of carbamide peroxide. J Esthet Dent 1999;11:259-64.

22. Gökay 0 , Müdjeci A, Algin E. In vitro peroxide penetration into the pulp chamber from newer bleaching products. Int Endod J 2005;38:516-20.

23. Pashley DH. Dentin: a dynamic substrate. Scan Microsc 1989;3:161-76. 